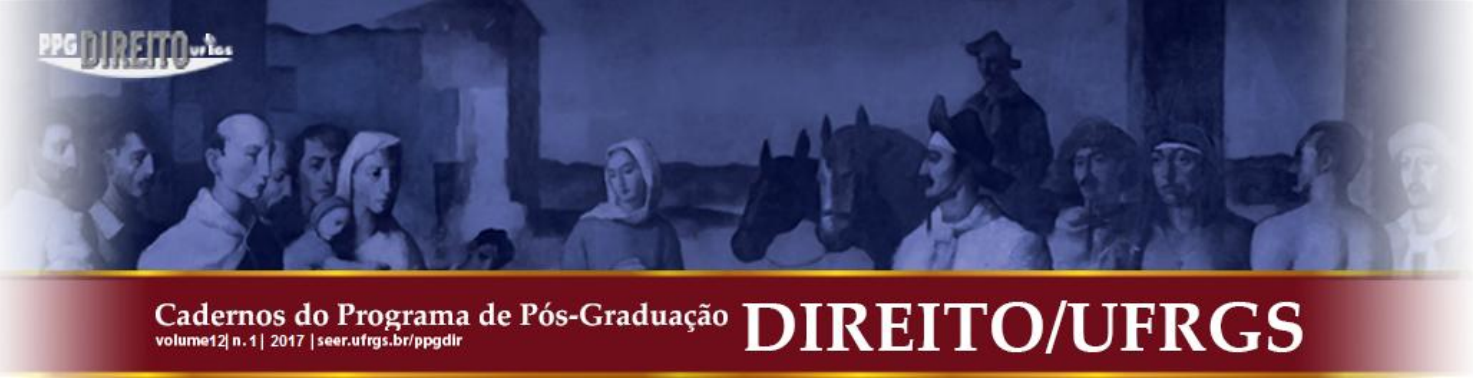

\title{
A DECADÊNCIA REVISITADA: CAUSA DE EXCLUSÃO DO CRÉDITO TRIBUTÁRIO?
}

\author{
REVISITING THE DECADENCE INSTITUT: A TAX LIABILITY EXCLUSION?
}

\author{
André Felipe Canuto Coelho* \\ Bruna Estima Borba**
}

\begin{abstract}
RESUMO: O presente artigo examina o crédito tributário, assim compreendida a relação jurídica formada entre o Estado e o particular visando à extinção do tributo. De acordo com o Código Tributário Nacional, referida relação jurídica é sujeita a hipóteses de extinção e de exclusão. O texto objetiva examinar tais hipóteses à luz de sua inserção nos planos jurídicos: de validade, de eficácia e de existência. Para tanto, torna-se necessária a distinção entre as formas de morte do crédito tributário em que ocorre o desaparecimento da própria relação jurídica. No caso da decadência, o próprio dever legal é afetado e, em consequência, a existência, a validade e a eficácia do vínculo jurídico desaparecem. Demonstra-se, ao final, que essa é a razão pela qual a decadência é causa de exclusão do crédito tributário, assim como o são a isenção e a anistia.
\end{abstract}

PALAVRAS-CHAVE: Crédito Tributário. Existência. Validade. Eficácia. Decadência.
ABSTRACT: This article aims to discuss the phenomenon of tax liability: the relationship between the citizen and the State considering tax extinction its fulfillment. In line with the National Brazilian Tax Code, such legal relationship is subject to the terms of extinction and exclusion. This paper intends to examine these hypotheses considering the plans of the legal world: validity, effectiveness and existence. Firstly, it was necessary to distinguish between forms of disappearance of tax legal relationship. In the case of decadence, the legal duty is affected and, in consequence. existence, validity and efficacy disappear. Theoretical evidence is found, therefore, for the reason why decadence is an exclusion cause of tax relationship, as well as exemption and amnesty.

KEYWORDS: Tax Liability. Existence. Validity. Efficacy. Decadence.

SUMÁRIO: Introdução. 1 O Estatuto Jurídico dos Fatos do Mundo. 2 O Fato Gerador. 3 O Nascimento do Crédito Tributário. 4 A Morte do Crédito Tributário. 4.1 Hipóteses em que há a Saída do Fato Gerador do Plano da Eficácia. 4.2 Hipóteses em que há a Saída do Fato Gerador do Plano da Validade. 4.3 Saída do Fato Gerador do Plano da Existência. 5 A Decadência como Hipótese de Exclusão do Crédito Tributário. Referências.

\section{INTRODUÇÃO}

Este estudo trata do tema crédito tributário analisando-o a partir dos planos de validade, eficácia e existência dos fatos no mundo jurídico. Para tanto, fez-se necessário estabelecer, entre as formas de extinção e exclusão do crédito tributário previstas no Código Tributário Nacional (CTN), aquelas que resultam no desaparecimento da própria relação

\footnotetext{
* Doutor em Ciência Política pela Universidade Federal de Pernambuco (UFPE). Mestre em Direito pela Universidade Federal de Pernambuco (UFPE). Graduado e Especialista em Economia pela Universidade Federal de Pernambuco (UFPE). Professor do Mestrado e Graduação em Direito da Faculdade Damas da Instrução Cristã, Pernambuco.

** Doutora e Mestre em Direito pela Universidade Federal de Pernambuco (UFPE). Especialista em Economia pela Universidade Federal de Pernambuco (UFPE). Graduada em Direito e Engenharia Mecânica pela Universidade Federal de Pernambuco (UFPE). Professora Adjunta de Direito Tributário e de Direito Financeiro do Centro de Ciências Jurídicas da Universidade Federal de Pernambuco (UFPE).
} 


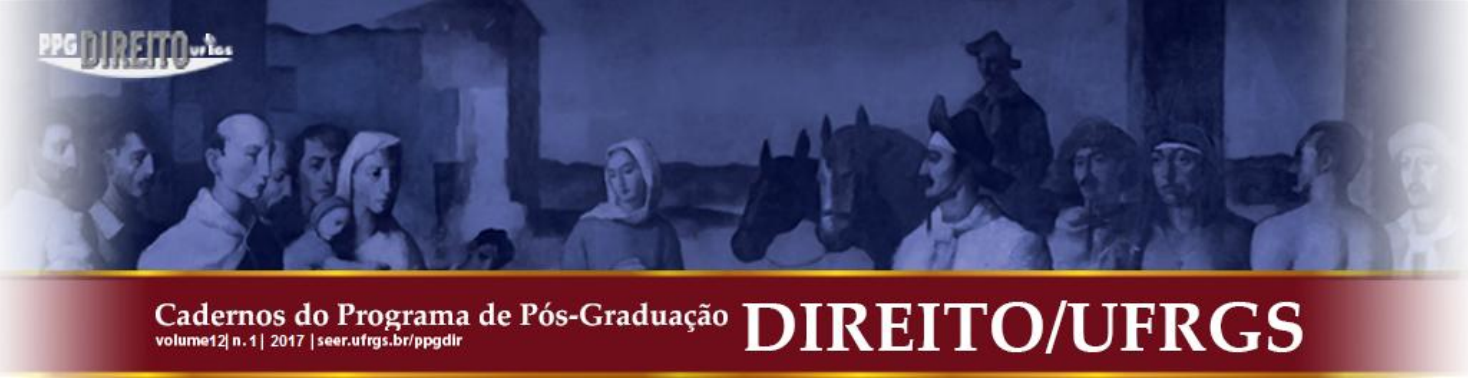

jurídica tributária que deram ensejo a seu surgimento. Tal tarefa será realizada a partir da análise da perda de validade, e/ou de eficácia, e/ou de existência da relação jurídica.

Considerar-se-á que a obrigação tributária nasce em razão da juridicização de um fato do mundo. Sua morte, por outro lado, decorrerá de uma das hipóteses previstas no CTN a título de extinção ou exclusão do crédito tributário. Em alguns casos, a morte do crédito pode se dar pela satisfação parcial ou total da pretensão - a exemplo da transação e do pagamento, respectivamente. Em outros, a morte pode resultar em um incumprimento - como ocorre na prescrição. Nessas situações, mantém-se, todavia, íntegro o dever jurídico que deu origem ao crédito, saindo a relação unicamente do plano da eficácia.

Contudo, há hipóteses em que a morte do crédito é consequência do desaparecimento do próprio dever jurídico, como evidenciam os casos de decadência, de isenção e de anistia. A relação obrigacional deixa de se fundar em qualquer vínculo jurídico, saindo do plano da existência.

Ademais de demarcar doutrinariamente a separação entre os institutos sob o aspecto da existência, da validade e da eficácia da relação jurídica tributária, tal distinção possui consequências práticas, vez que somente caberá restituição de valor pago a maior ou indevidamente pago a título de tributo nos casos em que o próprio dever jurídico é afetado, como ocorre com a decadência, a isenção e a anistia. No caso da prescrição, ao contrário, não cabe direito à repetição visto que o dever jurídico permanece existente, ainda que não mais eficaz.

Para realização deste estudo, será empreendida revisão bibliográfica, assim como se recorrerá à jurisprudência temática. Trata-se de investigação relevante porquanto aborda institutos - as hipóteses de extinção e exclusão do crédito tributário - dotados de características especiais no âmbito do direito tributário e cujos resultados levam à elucidação da existência ou não do direito à repetição de indébito.

\section{O ESTATUTO JURÍDICO DOS FATOS DO MUNDO}

As normas jurídicas têm como principal função formar o mundo jurídico (MELLO, 1995, p. 73). Como esclarece Pontes de MIRANDA (1970, p. 21): “Só o direito separa os fatos que ele faz serem jurídicos, precisando linhas entre o jurídico e o aquém ou o além do 


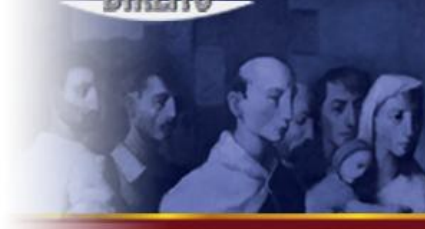

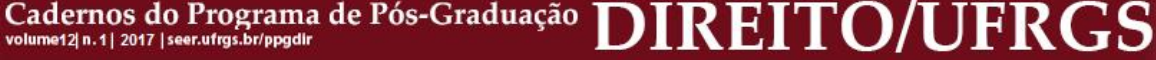

jurídico (não jurídico), como tira, ou acrescenta, ou altera alguns desses fatos para os fazer jurídicos".

É, portanto, a partir da incidência normativa que se dá a transformação do fato do mundo em fato jurídico ${ }^{1}$, consequência de um 'colorir' os fatos do mundo, no que Pontes de MIRANDA (1970, p. 6, 21) denominou de "princípio da esquematização do fáctico". A aceitação deste sistema lógico pressupõe a incidência de toda e qualquer regra matriz. Nesse mesmo sentido, explicou von TUHR (1947, p. 4): "Cuando existe in concreto el factum de cierta norma, el efecto jurídico se produce con necesidad lógica”.

Reportando-se à juridicização ${ }^{2}$ dos fatos do mundo, Tercio Sampaio FERRAZ JR. (2001, p. 165) classifica as normas de incidência em normas de conduta e de competência. As primeiras estabelecem obrigações, proibições, faculdades e impõem sanções, formando relações de coordenação entre os agentes. As últimas configuram poderes, delimitam seu exercício e preveem nulidades quando descumpridas, estabelecendo relações de subordinação entre os agentes.

A relação jurídica é, portanto, o cometimento normativo decorrente da incidência da norma sobre o fato (FERRAZ JR., 2001, p. 165). Nas palavras do já citado von TUHR (1947, p. 4), "Cada norma abstracta enuncia los hechos; si éstos existen, debe producirse el efecto jurídico".

Consoante Pontes de MIRANDA (1970, p. 6, 14), depois de entrar no mundo jurídico pelo procedimento de juridicização, o fato pode ser alternativamente desjuricidizado, ou permanecer jurídico, mas se exaurir pela satisfação, ou ser revogado pela vontade, ou ter sua validade declarada nula, ou ser anulado, ou rescindido, ou resolvido, ou resilido. Foi com essa inspiração que MELLO (1995, p. 72) propôs a sistematização das normas jurídicas

\footnotetext{
${ }^{1}$ Nesse estudo, utiliza-se a expressão fato jurídico em seu sentido amplo, abrangendo os fatos jurídicos stricto sensu e os atos jurídicos lato sensu. Fato é gênero, que se estende a toda ação material do homem ou todo evento exterior ou natural, independente do homem. (SILVA, 2008, p. 601). Os fatos, em sentido amplo, podem ser naturais, quando ocorrem sem intervenção humana (fatos jurídicos stricto sensu) ou voluntários, quando decorrentes da ação do homem, recebendo nesses casos a denominação de atos. Quando produzem efeitos jurídicos, tais fatos e atos passam a chamar-se fatos jurídicos e atos jurídicos lato sensu. Os atos jurídicos lato sensu, por sua vez se subdividem em atos jurídicos stricto sensu, negócios jurídicos e atos ilícitos. Compreendese como fato jurídico "todo e qualquer fato, de ordem física ou social, inserido em uma estrutura normativa". (REALE, 1994, p. 198).

${ }^{2}$ A juridicização dos fatos é compreendida, neste artigo, como sinônimo da absorção ou assunção de estatuto jurídico. Afasta-se, assim, do significado de "estratégia extrajudicial por meio da qual, sem perder o referencial do Direito, se estabelecem formas de resolução de conflitos baseadas no diálogo" exposto na doutrina. (FUNDAÇÃO GETÚLIO VARGAS, 2014).
} 


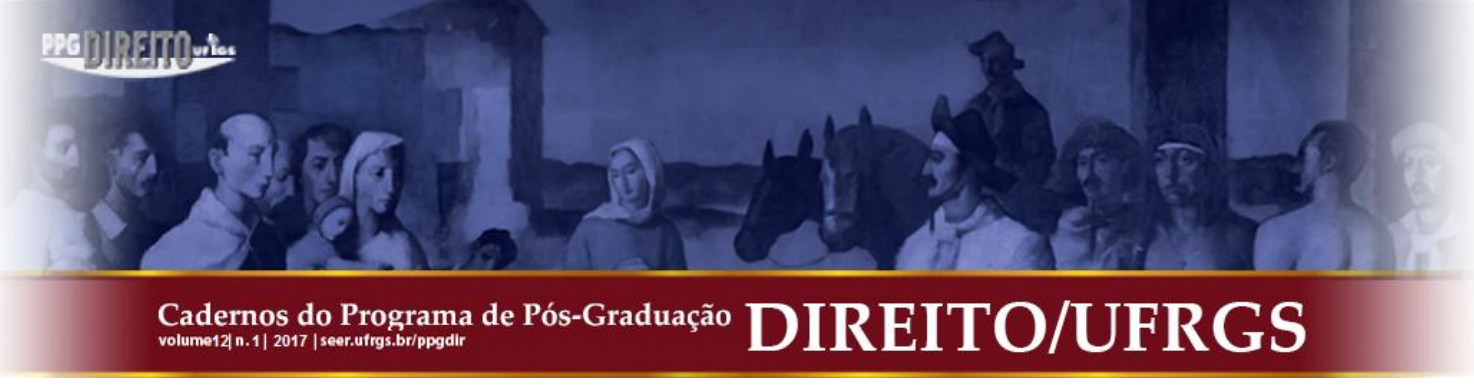

classificando-as em normas de juridicização, de pré-exclusão de juridicidade, de invalidação, de deseficacização e de desjuridicização.

Enquanto as normas de juridicização colorem os fatos do mundo para que eles ingressem no mundo jurídico, a norma de desjuridicização "enuncia que o fato jurídico vai deixar de ser jurídico, isto é, vai sair, ou desaparecer do mundo jurídico" (MIRANDA, 1970, p. 28). Ou, em outras palavras, a incidência das normas de desjuridicização tem "por consequência permitir que determinado fato jurídico seja retirado, excluído do mundo jurídico, trazendo-o de volta para o mundo fático” (MELLO, 1995, p. 73).

As normas jurídicas de invalidação, por sua vez, não retiram a juridicização do fato jurídico, "mas alcançam a sua validade”, de modo que o fato (MELLO, 1995, p. 75) não deixa de existir juridicamente, apenas perde a validade.

Contudo, Pontes de MIRANDA (1970, p. 13) segue além, explicando que, em razão da incidência de uma ou mais dessas normas, o mundo jurídico passa a ser composto por três planos: da existência, da validade e da eficácia.

Acompanhando o pensamento de Pontes de Miranda, MELLO (1995, p. 75) exemplifica as diferentes alocações dos fatos nos planos do mundo jurídico: I - fato juridicamente existente: I.1 - válido e eficaz: casamento entre homem e mulher capazes, sem impedimentos dirimentes e realizado perante autoridade competente. Nesse caso, há uma única incidência, a da norma de juridicização; I.2 - válido e ineficaz: testamento de pessoa capaz, feito com observância das formalidades legais, antes da ocorrência da morte do testador; I.3 - inválido e eficaz: casamento putativo, em que os contraentes desconhecem o grau de parentesco em linha reta entre si; I.4 - inválido e ineficaz: revogação da doação por ingratidão do donatário ${ }^{3}$. A ingratidão é o fato jurídico que permite a desjuridicização da doação, que retorna do mundo do direito ao mundo fático: o fato que era jurídico é excluído do mundo do direito retornando ao mundo fático, desvestido de toda a sua juridicidade; outro exemplo consiste no casamento entre homem e mulher incapazes; II - fato juridicamente inexistente desde sua origem, por causa de preexclusão de juridicização: as causas de exclusão de ilicitude ${ }^{4}$ - estado de necessidade, legítima defesa, estrito cumprimento do dever legal e exercício regular de direito; o casamento entre homem e mulher capazes, sem

\footnotetext{
${ }^{3}$ BRASIL. Código Civil, 2002, artigo 555.

${ }^{4}$ BRASIL. Código Penal, 1940, artigo 23.
} 


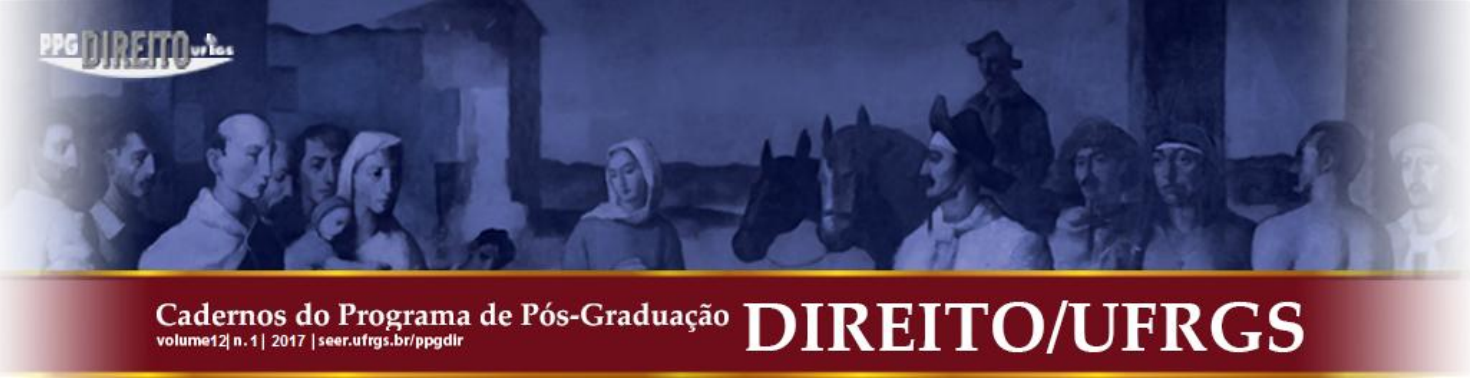

impedimentos dirimentes, realizado durante encenação de peça teatral. E, no caso do direito tributário, as hipóteses de não incidência, seja por atipicidade, seja por imunidade.

Destarte, é possível concluir que nas hipóteses em que há a saída do fato jurídico do plano da existência, a consequência lógica é a saída do fato dos planos da validade e da eficácia. Já nas hipóteses em que o fato jurídico sai do plano da validade, ocorre somente a saída do fato do plano da eficácia, mantida sua permanência no plano da existência. Por fim, as hipóteses em que há a saída do fato jurídico apenas do plano de eficácia não atingem sua permanência nos planos da existência e da validade.

\section{O FATO GERADOR}

A expressão fato gerador foi utilizada no Brasil desde a primeira sistematização do direito tributário, ocorrida com a publicação no Diário do Congresso Nacional de 7 de setembro de 1954, do Projeto $n^{\circ} 4.834$ que “institui o Código Tributário Nacional”. Na exposição de motivos se informava que referido projeto havia sido elaborado por comissão instituída em agosto de 1953, formada Rubens Gomes de Sousa e servidores do Ministério da Fazenda, presidida por Osvaldo Aranha, então ministro, e que tomava por base o anteprojeto elaborado pelo primeiro. Encaminhado para a Câmara dos Deputados, não chegou a ser votado.

Naquele documento o fato gerador foi conceituado pelo artigo 82 como "o estado de fato ou a situação jurídica definidos por lei tributária como dando origem, por si só ou por seus resultados, efetivos ou potenciais, o direito da Fazenda Pública constituir o crédito tributário correspondente" (BRASIL, 1954).

Denominava-se fato gerador, assim, tanto a situação concreta ocorrida no mundo dos fatos, quanto a sua abstrata previsão normativa. Rubens Gomes de SOUSA (1964, p. 64) utilizou em sua obra doutrinária de 1964 a expressão fato gerador sem evidenciar a distinção, certamente por lhe parecer óbvia. Para ele, fato gerador é "justamente a hipótese prevista na lei tributária em abstrato".

Em seu "Fato Gerador da Obrigação Tributária" redigido em 1964, Amílcar de Araújo FALCÃO $(2013$, p. 2) conceituou o fato gerador como "o conjunto de fatos ou o estado de fato do qual surge a obrigação tributária, em virtude da qual uma pessoa está obrigada a 
realizar ao Estado o pagamento de um tributo determinado" sem considerar necessário apontar a distinção entre fato e norma.

Apesar de haver indicado a lacuna doutrinária ao afirmar ainda em 1963 que "o fato gerador não gera coisa alguma, além de confusão intelectual”, Alfredo Augusto BECKER (1963, p. 288) não logrou identificar a razão de tal 'confusão' que, posteriormente, seria evidenciada pela indistinção entre a descrição normativa do fato e a sua ocorrência no mundo concreto.

Tal miscelânea conceitual permaneceu por ocasião da redação da Lei n ${ }^{\circ}$ 5.172/1966 pois, além de não constar em nenhum de seus dispositivos a diferenciação, o artigo 114 utiliza a expressão fato gerador da obrigação tributária principal para referir-se às duas acepções de fato gerador: "é a situação definida em lei como necessária e suficiente à sua ocorrência" (do próprio fato gerador).

Somente em 1973 foi explicitada essa distinção por obra de Geraldo Ataliba em seu "Hipótese de Incidência Tributária". A partir de então, passou-se a conceituar a hipótese de incidência tributária como "a descrição legal de um fato: é a formulação hipotética, prévia e genérica contida em lei, de um fato" (ATALIBA, 2008, p. 58). Já o fato gerador, ou fato imponível, é "o fato concreto, localizado no tempo e no espaço, acontecido efetivamente no universo fenomênico" (ATALIBA, 2008, p. 68).

Em 1984, Souto Maior BORGES (1999, p. 20) publicou "Obrigação Tributária", completando o ciclo "hipótese de incidência-fato gerador" com o estudo da sua consequência jurídica: o surgimento da relação jurídica tributária, a obrigação tributária. Para ele, “dado um certo antecedente normativamente previsto, um descritor normativo (Voraussetzung), deve-se seguir um certo consequente, um prescritor normativo (Folgerung)".

Esclarecendo a distinção entre dever jurídico e obrigação, Souto Maior BORGES (1999, p. 38) explica que a conexão entre obrigação e dever jurídico não é uma relação entre espécie e gênero, mas uma relação entre forma e conteúdo: enquanto o dever jurídico corresponde a uma categoria formal passível de preenchimento por conteúdos diversos, a obrigação é uma categoria jurídico dogmática, incorporando um único conteúdo entre os possíveis.

Vale mencionar ainda a colaboração de Paulo de Barros CARVALHO (1981, p. 79108) na edificação da doutrina tributária brasileira pela edição, em 1974, do livro "Teoria da Norma Tributária" estruturando a regra matriz de incidência tributária pela indicação precisa 


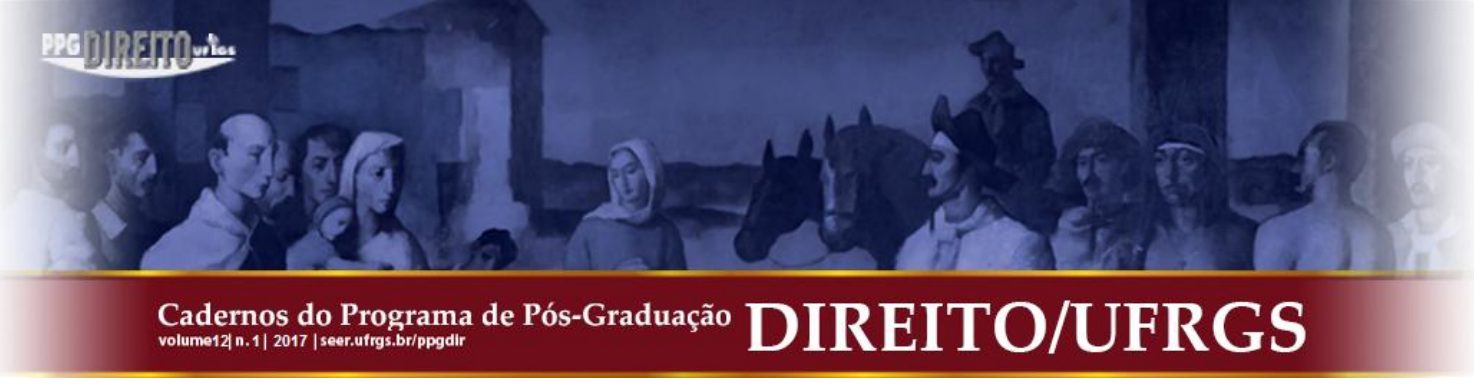

dos elementos que compõem a descrição normativa do fato gerador, isto é, os critérios essenciais da hipótese de incidência tributária, assim como da consequência jurídica imputada.

A análise do nascimento e da morte do crédito tributário em face da inserção e da exclusão do fato gerador nos planos do mundo jurídico não pode prescindir, assim, da compreensão de que a obrigação tributária e, em sequência lógica ao lançamento, sua consequência jurídica que é o crédito tributário, consistem em relações jurídicas surgidas de cometimento normativo. Ademais, é preciso compreender que tanto a obrigação tributária quanto o crédito tributário representam relações jurídicas que se distinguem em razão dos diferentes graus de eficácia.

Partindo dessas considerações, cabe indagar em qual dos planos do mundo jurídico existência, validade, eficácia - situa-se o crédito tributário quando atingido pelas modalidades de extinção e de exclusão, assim definidas no Código Tributário Nacional. Ou seja, quais as consequências das causas que fulminam o crédito tributário e que, neste estudo, são chamadas genericamente de causas da morte do crédito tributário?

Indaga-se, assim, o que ocorre com o crédito tributário - a relação jurídica tributária, individual e concreta, líquida e certa - frente às doze causas de extinção relacionadas taxativamente no artigo 156 do $\mathrm{CTN}$ : pagamento, compensação, transação, remissão, prescrição, decadência, conversão do depósito em renda, pagamento antecipado e sua homologação, consignação em pagamento, decisão administrativa irreformável, decisão judicial passada em julgado e dação em pagamento em bens imóveis? Nesse diapasão: o que ocorre, por sua vez, diante de uma das duas hipóteses da denominada exclusão do crédito previstas, também em rol taxativo, no artigo 175 do mesmo Código: isenção e anistia?

Perde o crédito apenas sua validade? Perde unicamente sua eficácia? Perde sua existência? Pretende-se demonstrar que há hipóteses em que a morte do crédito resulta exclusivamente em perda da eficácia da relação jurídica, permanecendo esta válida e existente, como se dá com a remissão. Em outras, resulta tanto em perda da validade quanto da eficácia da relação jurídica, como ocorre em razão da decisão administrativa definitiva que declara nulo por vício formal o lançamento, permanecendo ela existente, contudo. E ainda em outras hipóteses, como na decadência, a morte do crédito resulta em perda da própria existência, o que fará com que desapareçam também a validade e a eficácia da relação 


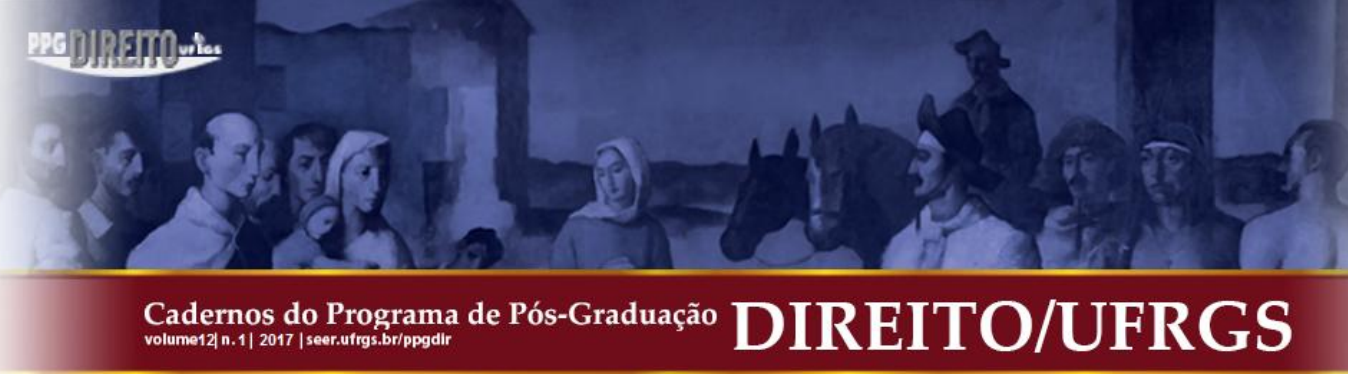

jurídica. É com lastro nessas considerações que se passa a analisar os planos de existência, validade e eficácia da relação jurídica tributária.

\section{O NASCIMENTO DO CRÉDITO TRIBUTÁRIO}

As normas de direito tributário que interessam a este estudo consistem em normas de direito material, conforme classificação formulada pela doutrina alemã que diferencia o direito tributário material, relativo à obrigação tributária ${ }^{5}$, do direito tributário formal, integrado pelas normas disciplinadoras da atividade administrativa de aplicação das normas de direito material (XAVIER, 1998, p. 53). São normas de juridicização (MIRANDA, 1970, p. 114; MELLO, 1995, p. 72) e de conduta (FERRAZ JR., 2001, p. 165) e possuem como finalidade primordial 'colorir' juridicamente o suporte fático - o fato gerador - fazendo surgir a obrigação tributária.

A obrigação tributária, relação jurídica que é, decorre de um cometimento normativo em razão da incidência da norma sobre o fato (FERRAZ JR., 2001, p. 165). Em realidade, as obrigações têm por origem uma norma - a lei ou o contrato - e por consequência a criação de um "vínculo objetivo em que ocorre a exigência de uma prestação" (FERRAZ JR., 2001, p. 159). Segundo Tércio Sampaio Ferraz a obrigação tributária, assim como o crédito tributário, são relações de coordenação que preveem o dever de A - sujeito passivo/devedor - e a faculdade de B - sujeito ativo/credor - de exigir o cumprimento do dever por parte de A (FERRAZ JR., 2001, p. 165).

Por mérito de Paulo de Barros CARVALHO (2009, p. 116) foi definida a estrutura lógica da relação jurídica tributária, denominada regra matriz de incidência, ou seja, um conjunto de dispositivos legais contendo o antecedente, o fator deôntico (o dever ser) e o consequente.

Enfim, no âmbito do Direito Tributário pode-se afirmar que o sistema funciona por meio da incidência da regra matriz dando-se, logicamente, o consequente nela prescrito: a obrigação tributária (CARVALHO, 1981, p. 30). Ocorrido, no mundo dos fatos, o 'estado de coisas'(HENSEL, 1956, p. 73) que coincide com a fattispecie prevista na norma, hipotética e

\footnotetext{
${ }^{5} \mathrm{O}$ direito tributário material tem por objeto o conjunto de normas que preveem as hipóteses de incidência tributária. (HENSEL, 1956, p. 72).
} 
abstratamente, surge então a pretensão por parte do Estado. A hipótese de incidência fattispecie, suporte fático, tatbestand - é, portanto, o pressuposto jurídico da obrigação.

Evidencia-se, assim, que a relação obrigacional preexiste ao lançamento. $O$ ato administrativo de lançamento - accertament na Itália (HENSEL, 1956, p. 157), liquidação (NABAIS, 2010, p. 317) em Portugal, liquidation de l'impôt na França (XAVIER, 1998, p. 3) - é regido pela lei material tributária vigente na data da ocorrência do fato gerador, denunciando a preexistência da relação jurídica à sua própria realização.

Logo, a obrigação, enquanto realidade jurídica, independe de haver ou não o lançamento. Esse é o regramento doutrinário e legal ${ }^{6}$ herdado pelo Brasil do Código Tributário Alemão de 1919. Para Albert HENSEL (1956, p. 156), a obrigação tributária compõe o valor do patrimônio do sujeito, pois "antes mesmo de estar o tributo numericamente determinado, pode ser objeto de garantia”, à exceção, claro, dos fatos geradores sob condição suspensiva.

Tal relação jurídica consiste em uma "relação jurídica entre duas pessoas em razão da qual uma parte (credora) possui a faculdade de pretender uma prestação da outra parte (devedora)",

Apesar de consistir em uma relação jurídica nos moldes do direito privado que vincula credor e devedor, o crédito tributário possui uma série de características particulares. A principal delas se deve à sua causa, pois enquanto a relação jurídica de direito privado decorre de um acordo bilateral de vontades, a formação da relação tributária se origina da lei e seus sujeitos e objeto não podem se afastar daqueles nela previamente fixados. A hipótese de incidência legal substitui, assim, a vontade das partes do direito privado ${ }^{8}$.

Em razão dessa constatação, muito se havia argumentado que a relação jurídica tributária consistiria em uma relação de poder e não em uma relação obrigacional. Todavia, o poder estatal se manifesta em um momento precedente, aquele da elaboração da lei. Existente, válida e vigente a lei tributária, as relações jurídicas a partir dela surgidas são relações obrigacionais, ainda que de direito público.

\footnotetext{
${ }^{6}$ BRASIL. Código Tributário Nacional, 1966, artigo 144.

7 "Relazione giuridica tra due persone, per effetto della quale una parte (creditore) ha facoltà di pretendere una prestazione dall'altra (debitore)". (HENSEL, 1956, p. 71).

8 "La fattispecie legale sostitusce, nel diritto obbligatorio d'imposta, la volontá del diritto privato". (HENSEL, 1956, p. 72). 


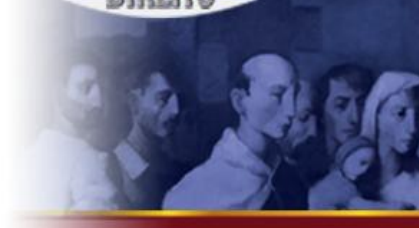

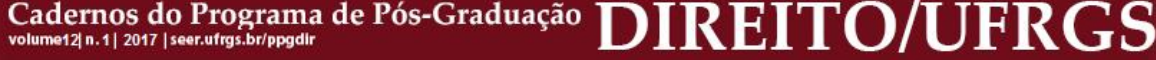

De acordo com a teoria dos graus sucessivos de eficácia, Alberto Xavier (1998, p. 588) trata do nascimento do crédito tributário compondo a dinâmica da sua constituição e exigibilidade:

Com a ocorrência do fato tributário, ela torna-se existente; no momento da prática do lançamento é formado um título, dotado de força executiva e que dá origem à relação jurídica abstrata em que se traduz o crédito tributário; neste momento - mas só nos tributos em que o lançamento precede necessariamente o pagamento - ela torna-se atendível; no momento da verificação do prazo de vencimento, torna-se exigível pelo credor e realizável pelo devedor; no momento em que se esgota o período de cobrança voluntária, sem que o pagamento tenha sido efetuado, torna-se exequível.

Em outras palavras, na obrigação tributária há relação jurídica de eficácia mínima, pois o direito subjetivo existe de um lado, assim como o dever jurídico de outro. No entanto, não há ainda possibilidade de exercício da pretensão, em razão de o direito não ser exigível. No crédito tributário há um maior grau de eficácia, uma vez que existe a possibilidade de exercício da pretensão.

Tal compreensão da questão dirimiu as dúvidas acerca da origem da relação jurídica tributária em torno da qual digladiavam as teorias constitutivistas e declarativistas, pacificando o entendimento de que o lançamento é ato declaratório da obrigação e constitutivo do crédito: "Essa consequência traduzir-se-ia na atribuição de uma dupla eficácia ao lançamento: uma eficácia declarativa da situação tributária subjacente (a obrigação tributária); uma eficácia constitutiva da situação tributária abstrata” (XAVIER, 1998, p. 568).

Não é correto, assim, pretender-se associar apenas a obrigação tributária ao conceito de Schuld (dever jurídico), restando para o crédito tributário, que nasce com a prática do ato administrativo de lançamento, a vinculação ao conceito de Haftung, decorrente do inadimplemento da obrigação, representando uma relação de responsabilidade. A primeira teria sede no artigo 113, parágrafo único do Código Tributário Nacional, a segunda, nos arts. 139 e 142 do mesmo Código. Isto porque a obrigação e o crédito consistem em relações jurídicas contendo tanto dever jurídico como possibilidade de responsabilização pelo incumprimento desse dever. Distinguem-se, apenas, quanto ao grau de eficácia.

Para Paulo de Barros CARVALHO (2009, p. 359-360) o crédito tributário é direito subjetivo de que é portador o sujeito ativo de uma obrigação tributária e que lhe permite exigir o objeto prestacional, representado por uma importância em dinheiro. Para Tercio 


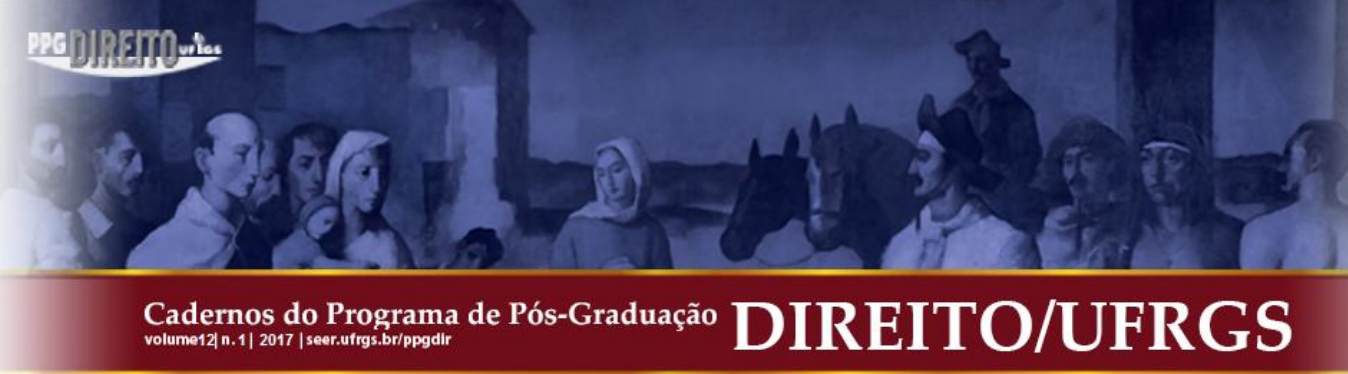

Sampaio FERRAZ (2001, p. 159), é o dever jurídico do sujeito passivo decorrente do vínculo criado pela obrigação.

O artigo 139 do Código Tributário Nacional limita-se a afirmar que "o crédito tributário decorre da obrigação principal e tem a mesma natureza desta" o que quer significar que tanto a obrigação tributária principal quanto o crédito tributário são relações jurídicas, só que, no crédito, a prestação é líquida e certa, enquanto na obrigação a prestação ainda não foi liquidada. Logo, pode-se concluir que o crédito tributário é uma relação jurídica obrigacional resultante de dois outros institutos, a obrigação tributária - relação jurídica individual e concreta, ainda não líquida e certa - e o lançamento - ato administrativo pelo qual se torna líquida e certa a obrigação tributária.

Deve-se atentar, ainda, que o lançamento é ato administrativo que declara a existência da obrigação, assim compreendida a relação jurídica material, ou de eficácia mínima, que corresponde ao direito subjetivo do sujeito ativo e ao dever jurídico do sujeito passivo. Com o lançamento, por outro lado, constitui-se o crédito, relação jurídica formal, de eficácia maior.

Conclui-se, por fim, que o crédito tributário, vínculo jurídico entre devedor e credor, nasce com a juridicização do fato, tratando-se o lançamento de mero ato administrativo que confere maior grau de eficácia à relação jurídica tributária, permitindo o exercício da pretensão da parte ativa/credora.

\section{A MORTE DO CRÉDITO TRIBUTÁRIO}

A morte do crédito tributário decorre de "qualquer ato ou fato que liberte o sujeito passivo (devedor) da sujeição em que se encontra ao poder jurídico do sujeito ativo (credor), fazendo desaparecer o direito deste contra aquele" (SOUSA, 1964, p. 79).

Rubens Gomes de SOUSA (1964, p. 79-80) esclarece que, apesar de o crédito tributário resultar da obrigação tributária, há autonomia relativa entre eles. O crédito tributário como realidade formal pode ser afetado sem que o seja a sua substância, a obrigação. Assim ocorre nas formas de extinção do crédito previstas no artigo 156 do CTN, como o pagamento, por exemplo, em que o crédito desaparece e, no entanto, a obrigação tributária respectiva não é afetada. Por outro lado, pode ocorrer que um crédito tributário seja formalizado sem que tenha ocorrido o fato gerador da obrigação tributária. Neste caso, não existe obrigação, mas apenas um crédito tributário, como realidade meramente formal.

Cadernos do Programa de Pós-Graduação em Direito PPGDir./UFRGS | Edição Digital | Porto Alegre | Volume XII | Número 1 | 2017 | P. 278 - 299 


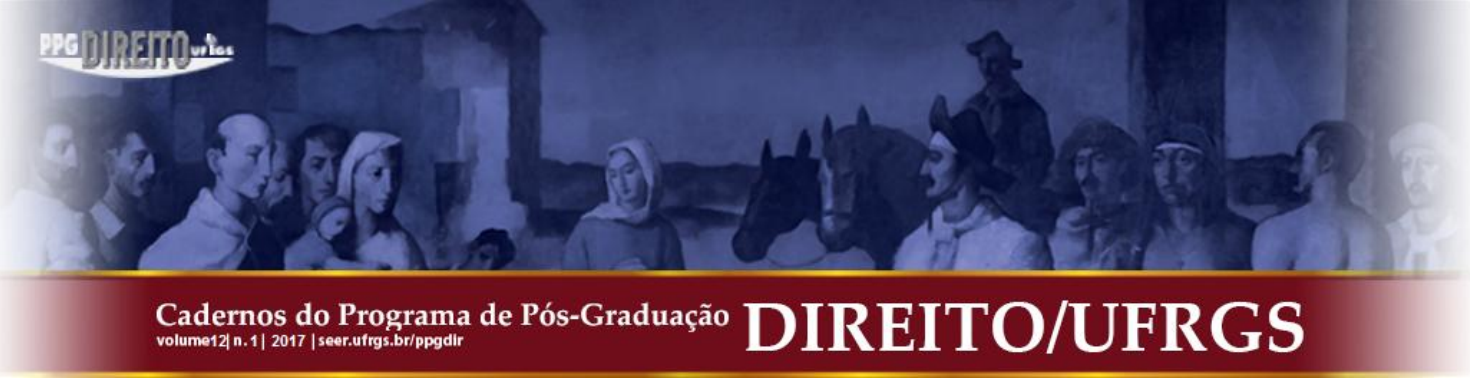

Fulminado o lançamento por constatada sua improcedência conforme decisão administrativa definitiva ou decisão judicial transitada em julgado, perece o crédito tributário afetando, igualmente, a obrigação tributária.

A relação jurídica tributária é, por sua natureza, destinada à satisfação da pretensão do credor. Por essa razão, a forma mais comum de morte do crédito tributário se dá por exaurimento da pretensão, isto é, do direto subjetivo do credor simultaneamente com a extinção do dever jurídico do devedor.

Todavia, há outros modos pelos quais pode ocorrer a morte de uma relação jurídica qualquer. Isto porque, após ingressar no mundo jurídico pela juridicização, o fato pode: (i) ser desjuricidizado; (ii) permanecer jurídico, mas se exaurir pela satisfação; (iii) ser revogado por vontade; (iv) ter sua validade declarada nula; (v) ser anulado, ou rescindido, ou resolvido, ou resilido (MIRANDA, 1970, p. 114). No caso da relação jurídica tributária, entretanto, não cabe falar em revogação, haja vista a ausência de discricionariedade que a rege.

Dessa forma, o artigo 156 do CTN contempla doze hipóteses denominadas de causas de extinção do crédito tributário, relacionadas taxativamente: pagamento, compensação, transação, remissão, prescrição, decadência, conversão do depósito em renda, pagamento antecipado e sua homologação, consignação em pagamento, decisão administrativa irreformável, decisão judicial passada em julgado e dação em pagamento em bens imóveis. Em seu artigo 175, por sua vez, são elencadas hipóteses chamadas de causas de exclusão do crédito: isenção e anistia.

Contudo, o legislador não teve o cuidado de conceituar a extinção e a exclusão do crédito, nem tampouco de especificar, em relação a essas causas de extinção e exclusão, como estará sendo atingida a relação que fundamenta juridicamente o crédito e a obrigação.

A questão deve, portanto, ser estudada à luz da incidência das normas jurídicas - de juridicização, de pré-exclusão de juridicidade, de invalidação, de deseficacização e de desjuridicização (MELLO, 1995, p. 72) - e da pertença aos planos do mundo jurídico - de existência, validade e eficácia (MIRANDA, 1970, p. 13).

Como exposto anteriormente, nas hipóteses em que há a saída do fato jurídico do plano da existência, a consequência lógica é a saída do fato dos planos da validade e da eficácia. Já nas hipóteses em que o fato jurídico sai do plano da validade, ocorre somente a saída do fato do plano da eficácia, mantida sua permanência no plano da existência. Por fim, 
as hipóteses em que há a saída do fato jurídico apenas do plano de eficácia não atingem sua permanência nos planos da existência e da validade.

Nessa perspectiva, propõe-se o seguinte esquema para exame das causas denominadas de extinção e de exclusão do crédito tributário: (i) hipóteses em que há a saída do fato jurídico (fato gerador) apenas do plano de eficácia, mantida sua permanência nos planos da existência e da validade; (ii) hipóteses em que há a saída do fato jurídico (fato gerador) do plano da validade, acarretando somente a saída do plano da eficácia, mantida sua permanência no plano da existência; (iii) hipóteses em que há a saída do fato jurídico (fato gerador) do plano da existência, acarretando em consequência a saída dos planos da validade e da eficácia. Tais hipóteses serão analisadas em sequência.

\subsection{Hipóteses em que há a Saída do Fato Gerador do Plano da Eficácia}

Entre as formas de extinção previstas no artigo 156 do CTN há sete hipóteses em que é previsto o adimplemento da obrigação, isto é, satisfação, ainda que parcial, da pretensão: pagamento, compensação, transação, conversão do depósito em renda, pagamento antecipado e sua homologação, consignação em pagamento e dação em pagamento em bens imóveis.

Nesses casos, permanece a juridicização do fato, mas a morte do crédito tributário decorre do exaurimento da pretensão. Representam, portanto, casos em que a obrigação tributária permanece existente, válida e, no entanto, não é mais eficaz uma vez que se exauriu a pretensão do credor, que foi satisfeita. Se assim não fosse, o pagamento do tributo, ainda que devido, geraria direito à repetição do indébito, pela desjuridicização da obrigação.

Nos casos de remissão e de prescrição dá-se extinção do crédito sem, contudo, haver o exaurimento da obrigação, pois a pretensão do credor frente ao devedor não foi satisfeita. São casos em que a obrigação não é afetada, apenas o crédito.

Deste modo, na prescrição a obrigação é mantida sem que a pretensão seja satisfeita pois, em razão do transcurso do tempo, o credor vê fulminada a possibilidade de exercê-la. Há, nesses casos, um procedimento de perda de eficácia da relação jurídica que não afeta existência ou a validade do fato jurídico, atingindo apenas seus efeitos (MELLO, 1995, p. 76).

Da mesma forma, o perdão do crédito pela remissão deixa intocada a obrigação, atingindo unicamente a eficácia da relação jurídica. Nesse caso o crédito é devido, mas é 


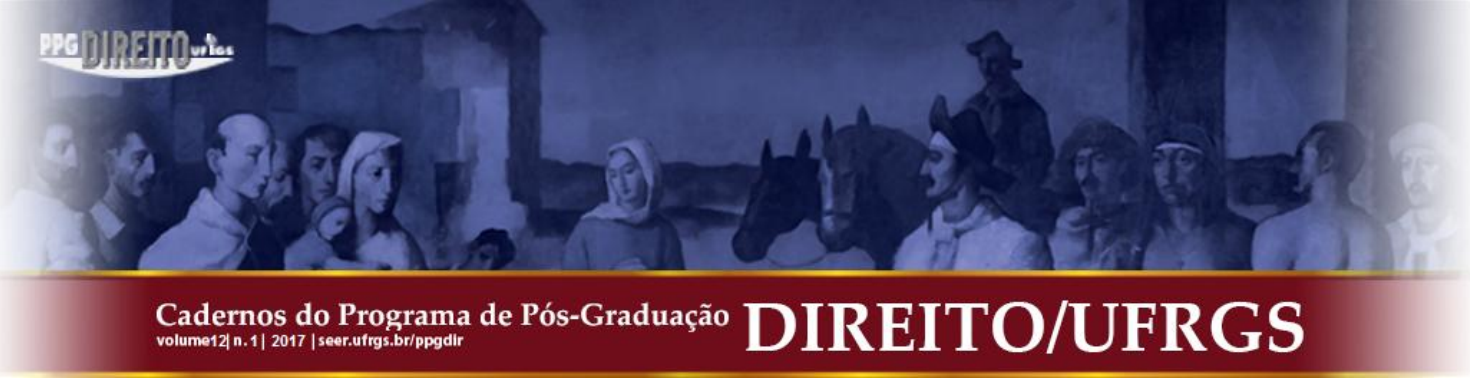

perdoado. Reitere-se que no campo do direito tributário não cabe falar em revogação em razão da vinculação e obrigatoriedade que orientam a constituição do crédito tributário.

Nos casos até aqui analisados o crédito desaparece, porém a obrigação não é atingida por essa morte. Ela apenas é satisfeita, adimplida integralmente ou não, como no particular caso da prescrição, por ver-se impedida de ser oposta ao devedor.

Pode-se afirmar, assim, que no pagamento, na compensação, na transação, na conversão do depósito em renda, no pagamento antecipado e sua homologação, na consignação em pagamento e na dação em pagamento em bens imóveis, assim como na prescrição e na remissão, morre o crédito, porém permanece a obrigação. Se assim não fosse, em todas as vezes que se pagasse o crédito, seria possível alegar haver desaparecido também a obrigação, cabendo restituição do indébito. Dessa forma, ao pagar crédito prescrito, não pode o sujeito passivo pleitear repetição de indébito, exceto se "provar que o pagamento era indevido por alguma razão de direito" (SOUSA, 1964, p. 96).

\subsection{Hipóteses em que há a Saída do Fato Gerador do Plano da Validade}

Pode ocorrer de o sujeito passivo contestar a exigência ao optar pela via administrava ou judicial, visando à desconstituição do crédito tributário. De outro lado, a própria administração tributária, em razão de seu poder de autotutela, pode rever o lançamento nos termos do artigo 145 do CTN.

Nessas situações, será proferida uma decisão administrativa definitiva ou uma decisão judicial transitará em julgado, conforme o caso, determinando a invalidade do crédito tributário nos termos do artigo 156 do CTN. Seja em razão de vício formal ou de erro material, o lançamento será declarado improcedente, extinguindo a pretensão do credor. Essa declaração da invalidade afetará, aditivamente, a eficácia do crédito tributário, mas não fará desaparecer o próprio fato jurídico objeto do julgamento.

\subsection{Saída do Fato Gerador do Plano da Existência}

Há, no campo do direito tributário, normas que preveem a desjuridicização do fato gerador: a isenção, a anistia e a decadência. O CTN prevê, em seu artigo 175, duas hipóteses de exclusão do crédito tributário: isenção e anistia. 


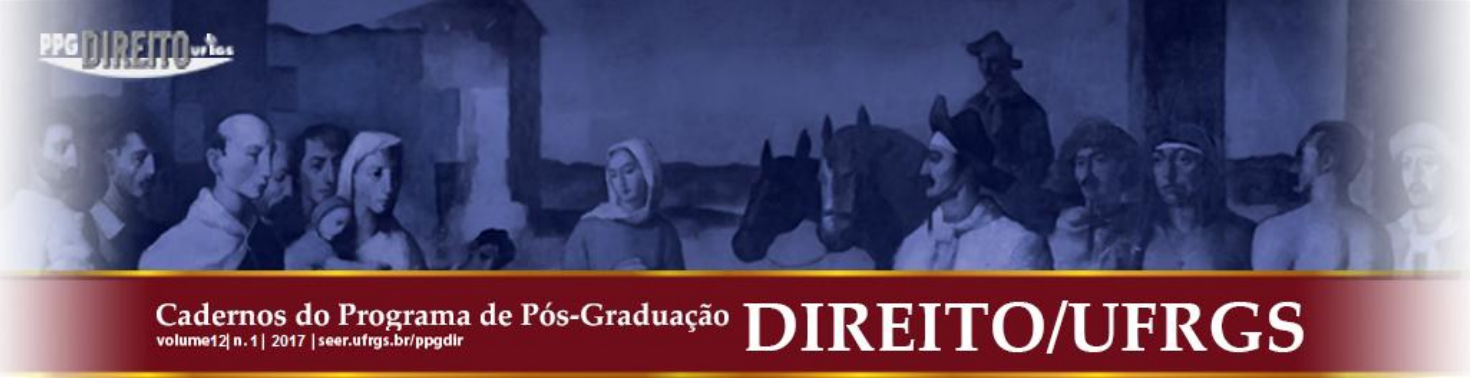

$\mathrm{Na}$ isenção, há uma exclusão do “crédito", ou seja, uma vedação legal à constituição do crédito tributário. Pois a dispensa do pagamento de crédito tributário lançado, devidamente constituído, ocorre por meio da remissão - ou perdão - que é causa de extinção do crédito tributário.

Para melhor compreensão, deve-se analisar quando há e quando não há incidência da norma sobre os fatos do mundo. A não incidência "é a situação em que um tributo não é devido por não ter ocorrido o respectivo fato gerador" (SOUSA, 1964, p. 72). A não incidência pode decorrer da atipicidade, a exemplo do piscar de olhos, fato que não corresponde a nenhuma hipótese de incidência tributária. Pode, também, decorrer da imunidade que é a determinação constitucional de não exercício da competência tributária. A imunidade é uma norma de incompetência tributária sendo por isso considerada uma exclusão ou supressão do poder de tributar. Para as pessoas, situações ou operações imunes, não há ocorrência do fato gerador. Daí porque a imunidade é chamada pela doutrina (CANTO, 1964, p. 190; COELHO, 2009, p. 141) e pela jurisprudência ${ }^{9}$, de "hipótese de não incidência constitucionalmente qualificada".

$\mathrm{Na}$ isenção, de outra parte, há uma dupla incidência normativa: a da lei que determina a exigência genérica sobre fato, situação ou operação e, em sequência, a da lei isentiva também denominada lei de atenuação ou lei de exceção - que exclui ou afasta a incidência sobre o fato, situação ou operação particularizado por algum aspecto nela especificamente indicado.

Explica Luciano AMARO (2009, p. 281), “a isenção atua geralmente num sistema de par de normas, em que uma é a regra, outra é a exceção; uma é gênero (regra), a outra é espécie (excepcionada)".

Ressalte-se que, para Rubens Gomes de SOUSA (1964, p. 72), a isenção consiste em "dispensar o pagamento de um tributo devido". Para Souto Maior BORGES (1980, p. 182183) a isenção corresponde a uma hipótese de não incidência legalmente qualificada. Contudo, o entendimento dos eminentes doutrinadores, apesar de respeitável, difere daquele exposto neste estudo em que se advoga a tese da dupla incidência normativa.

\footnotetext{
${ }^{9}$ A distinção entre imunidade e isenção foi retratada pelo STF conforme segue: “a imunidade tributária é matéria típica do texto constitucional enquanto a de isenção é versada na lei ordinária" (BRASIL. Supremo Tribunal Federal. ADI 2.006-MC).
} 


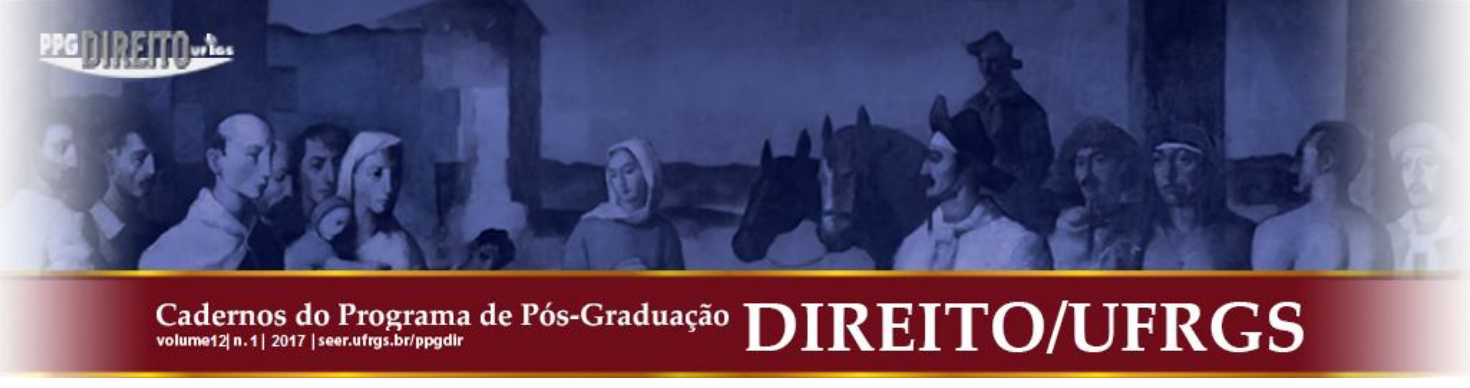

Há, portanto, dois momentos jurídicos para a configuração da isenção: o primeiro, a previsão legal de um fato gerador; o segundo, outra previsão legal, afastando a aplicação da primeira lei sobre determinados fatos ou situações. A isenção, regulada nos artigos 176 a 179 do CTN é, portanto, uma forma de exclusão do crédito tributário por representar uma impossibilidade de existência da relação jurídica vez que sobre o fato é excluída a incidência da norma tributária.

Quando se tratar de reconhecimento de isenção, a decisão administrativa ou judicial, se for o caso, concluirá pela não incidência da lei tributária sobre determinado fato. Haverá “dois suportes fáticos: o da regra jurídica e o da regra jurídica de atenuação ou exceção. A limitação é apenas a negação do suporte fáctico da regra jurídica geral” (MIRANDA, 1970. P. 26). Dar-se-á, assim, além da desconstituição do crédito tributário, uma invalidação da própria obrigação, com consequente saída do fato dos planos da existência, da validade, e da eficácia.

A anistia fiscal é referida nos artigos 175 e 180 a 182 do CTN como exclusão do 293 crédito tributário relativamente a penalidades. Assemelha-se à anistia penal por considerar que os fatos então considerados ilícitos, em face da edição de lei posterior, não mais o serão. As leis que concedem anistia são, assim, leis elaboradas para produzir efeitos no passado. Há, na hipótese de anistia, a exemplo da isenção, uma dupla incidência normativa: a incidência da lei vigente à época do fato infracional e, em sequência cronológica, a incidência retroativa da lei anistiadora que afasta a lei originária, excluindo o crédito decorrente da multa aplicada.

Para Rubens Gomes de SOUSA (1964, p. 90) na anistia as multas são perdoadas por lei. Parte da doutrina acompanha esse entendimento, considerando-a uma forma de remissão, perdão, ou dispensa legal do pagamento de multas (COELHO, 2009, p. 775). Luciano AMARO (2009, p. 455), por outro lado, defende que a anistia é "o perdão de infrações, do que decorre a inaplicabilidade da sanção. Não é a sanção que é anistiada; o que se perdoa é o ilícito".

Não obstante, tais teses não são acolhidas neste estudo posto que se considera mais adequada a teoria da dupla incidência normativa. Dessarte, se determinada declaração deveria ter sido apresentada em certa data e não foi, cabe a aplicação de penalidade pecuniária pelo descumprimento da obrigação acessória. Editada uma lei que extingue a penalidade pelo descumprimento da referida obrigação - a de apresentar a declaração em certa data, por exemplo, perde o fato relevância jurídico-tributária. 
A desconstituição do crédito, nesse caso, atinge também a obrigação tributária, com consequente saída do fato jurídico praticado pelo contribuinte - que corresponde ao fato gerador - do plano da existência e, consequentemente, da validade e da eficácia.

\section{A DECADÊNCIA COMO HIPÓTESE DE EXCLUSÃO DO CRÉDITO TRIBUTÁRIO}

A decadência é instituto que regula a perda de direito em razão do transcurso do tempo: jus non sucurrit dormientibus. É prevista no artigo 156 do CTN como modo de extinção do crédito tributário, juntamente com a prescrição.

Distingue-se a decadência da prescrição, pois na primeira opera-se a perda do direito material e na prescrição dá-se a perda do direito da ação que assegura o direito material ${ }^{10}$. Ambas são aspectos da morte do crédito tributário particularizados, entre outras razões, por não ocorrer a satisfação da pretensão do credor.

Ocorre a decadência quando a Fazenda Pública não constitui, por intermédio do lançamento e depois de nascida a obrigação, o crédito tributário. Segundo o então Ministro Moreira Alves (BRASIL. Supremo Tribunal Federal, 1982), “o direito de lançar é um direito potestativo modificativo" pois o fisco transforma a obrigação tributária ilíquida em obrigação tributária líquida, isto é, no próprio crédito tributário. Ressalte-se que o $\mathrm{STJ}^{11}$ já pacificou o entendimento, relativamente aos tributos sujeitos a lançamento por homologação, que a apuração e declaração do débito pelo próprio contribuinte constitui o crédito, prescindindo de lançamento e contando-se apenas o prazo prescricional. Relativamente aos tributos sujeitos a lançamento de ofício e por declaração, a constituição do crédito se dá pela ciência válida do sujeito passivo, seja por meio de notificação de lançamento ou de auto de infração.

Em outras palavras, a decadência ocorre quando o Fisco não apura, por intermédio do lançamento, depois de nascida a obrigação, o crédito tributário. Por essa razão, diz-se que o lançamento é ato declaratório da obrigação tributária e constitutivo do crédito tributário. Porém, enquanto a prescrição atinge unicamente o direito de exigir o crédito, a decadência atinge o próprio direito material a esse crédito, eliminando a obrigação tributária por atingir o fato gerador que a criou. Há na decadência, portanto, a saída do fato jurídico praticado pelo

\footnotetext{
${ }^{10}$ SOUSA, 1964, p. 95.

${ }^{11}$ BRASIL. Superior Tribunal de Justiça. Súmula 436. A entrega de declaração pelo contribuinte, reconhecendo o débito fiscal, constitui o crédito tributário, dispensada qualquer providência por parte do Fisco. 
contribuinte - que corresponde ao fato gerador - do plano da existência e, consequentemente, da validade e da eficácia.

Seguindo o esquema da alocação nos planos do mundo jurídico ${ }^{12}$ já exposto anteriormente, os fatos do mundo podem ser assim caracterizados: I - fato juridicamente existente: I.1 - válido e eficaz; I.2 - válido e ineficaz; I.3 - inválido e eficaz: I.4 - inválido e ineficaz; II - fato juridicamente inexistente desde sua origem, por causa de preexclusão de juridicização.

Viu-se que há hipóteses, como no pagamento, na compensação, na transação e na dação em pagamento, em que a morte do crédito decorre da satisfação total ou parcial da pretensão. Já na prescrição, na decisão administrativa definitiva e na decisão judicial transitada em julgado, também se dá a morte do crédito ainda que não tenha havido o cumprimento da prestação e a satisfação da pretensão. Em quaisquer dessas situações, entretanto, mantém-se íntegro o dever jurídico que deu origem ao crédito, saindo a relação unicamente dos planos da validade e/ou da eficácia, conforme o caso.

Há hipóteses em que a morte do crédito é consequência do desaparecimento do próprio dever jurídico, como ocorre nos casos de isenção e de anistia. Nesses casos, a relação obrigacional deixa de se fundar em qualquer vínculo jurídico, saindo do plano da existência. É o que ocorre igualmente na decadência, em que há a perda do próprio direito material. Ou seja, o fato jurídico deixa de revestir-se da condição de fato gerador, pois não é mais capaz de gerar qualquer obrigação e, consequentemente, nenhum crédito tributário.

A decadência, portanto, torna o fato juridicamente inexistente e, por decorrência, inválido e ineficaz. Ressalte-se que igual fenômeno ocorre com a isenção e a anistia, visto que, nesses casos, o fato que gerou a obrigação deixa de existir em razão da lei isentiva e da lei anistiadora, respectivamente. Mister observar ainda que, na prescrição, o fato também se torna juridicamente inexistente e ineficaz, porém permanece válido até porque somente o direito de ação é atingido.

Enfim, é possível concluir que nas hipóteses em que há a saída do fato jurídico do plano da existência - isenção, anistia e decadência - a consequência lógica é a saída do fato dos planos da validade e da eficácia. Já nas hipóteses em que o fato jurídico sai do plano da validade, ocorre somente a saída do fato plano da eficácia, mantida sua permanência no plano

\footnotetext{
${ }^{12}$ Pelo artigo $7^{\circ}$ do Ato Complementar no 36/1967 (BRASIL, 1967). 


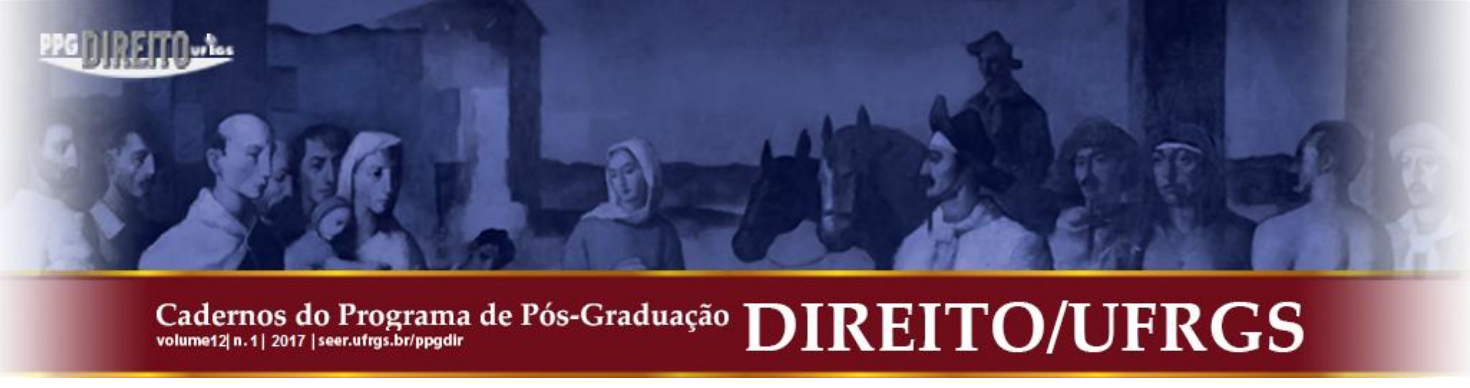

da existência. Por fim, as hipóteses em que há a saída do fato jurídico unicamente do plano de eficácia não atingem sua permanência nos planos da existência e da validade.

Em que pese não haver sido essa a escolha do legislador, posto que tanto no projeto do código tributário elaborado em 1954 (artigo 118, inciso IV), quanto por ocasião da edição da Lei $\mathrm{n}^{\circ}$ 5.172/1966 (art. 156, inciso V), a decadência constou como causa de extinção do crédito, acredita-se haver sido demonstrado mediante a presente análise crítica que a decadência é hipótese de exclusão do crédito tributário.

Resumindo, pode-se elaborar o seguinte esquema referenciado à morte do crédito tributário para associar a decadência à exclusão do crédito tributário, ao lado da isenção e da anistia.

\begin{tabular}{|c|c|c|}
\hline \multicolumn{3}{|c|}{ Tabela - Morte do crédito tributário } \\
\hline Instituto & $\begin{array}{c}\text { Efeitos sobre os planos do mundo } \\
\text { jurídico }\end{array}$ & $\begin{array}{c}\text { Efeitos sobre o crédito } \\
\text { tributário }\end{array}$ \\
\hline $\begin{array}{l}\text { Isenção } \\
\text { Anistia } \\
\text { Decadência }\end{array}$ & $\begin{array}{l}\text { Saída do plano da existência e, por } \\
\text { consequência, dos planos de } \\
\text { validade e eficácia }\end{array}$ & $\begin{array}{l}\text { Exclusão do crédito } \\
\text { tributário: morte do crédito, } \\
\text { atingindo também } \\
\text { obrigação tributária e } \\
\text { excluindo o fato jurídico do } \\
\text { mundo da incidência }\end{array}$ \\
\hline $\begin{array}{l}\text { Decisão } \\
\text { administrativa } \\
\text { definitiva } \\
\text { favorável ao } \\
\text { sujeito passivo } \\
\text { Decisão judicial } \\
\text { transitada } \\
\text { favoravelmente }\end{array}$ & $\begin{array}{l}\text { Saída do plano da validade e, por } \\
\text { consequência, do plano da eficácia. } \\
\text { Permanência no plano da existência }\end{array}$ & $\begin{array}{l}\text { Extinção do crédito: morte } \\
\text { do crédito, atingindo } \\
\text { também a obrigação } \\
\text { tributária sem excluir o fato } \\
\text { jurídico do mundo da } \\
\text { incidência }\end{array}$ \\
\hline $\begin{array}{l}\text { Pagamento } \\
\text { Compensação } \\
\text { Transação } \\
\text { Conversão do } \\
\text { depósito em renda } \\
\text { Pagamento } \\
\text { antecipado e sua } \\
\text { homologação } \\
\text { Consignação em } \\
\text { pagamento } \\
\text { Dação em } \\
\text { pagamento em } \\
\text { bens imóveis } \\
\text { Remissão } \\
\text { Prescrição }\end{array}$ & $\begin{array}{l}\text { Saída do plano da eficácia. } \\
\text { Permanência nos planos da } \\
\text { existência e da validade. }\end{array}$ & $\begin{array}{l}\text { Extinção do crédito: morte } \\
\text { do crédito, atingindo } \\
\text { também a obrigação } \\
\text { tributária sem excluir o fato } \\
\text { jurídico do mundo da } \\
\text { incidência }\end{array}$ \\
\hline
\end{tabular}




\section{DIREITO/UFRGS}

\section{REFERÊNCIAS}

AMARO, Luciano. Direito tributário brasileiro. São Paulo: Saraiva, 2009.

ATALIBA, Geraldo. Hipótese de incidência tributária. São Paulo: Malheiros, 2008.

BECKER, Alfredo Augusto. Teoria geral do direito tributário. São Paulo: Saraiva, 1963.

BORGES, José Souto Maior. Obrigação tributária (uma introdução metodológica). São Paulo: Malheiros, 1999.

Isenções tributárias. São Paulo: Sugestões Literárias, 1980.

BRASIL. Código Civil. Lei 10.406, de 10 de janeiro de 2002. Disponível em: <http://seer.ufrgs.br/index.php/ppgdir/editor/submission/72446>. Acesso em: 05 abril 2017.

. Código Penal. Decreto-Lei 2.848, de 07 de dezembro de 1940. Disponível em: < http://www.planalto.gov.br/ccivil_03/decreto-lei/Del2848compilado.htm>. Acesso em: 05 abril 2017.

Código Tributário Nacional. Lei 5.172, de 25 de outubro de 1966. Disponível em: <http://www.planalto.gov.br/ccivil_03/leis/L5172.htm>. Acesso em: 05 abril 2017.

Projeto 4.834, de 1954. Disponível em: <http://imagem.camara.gov.br/Imagem /d/pdf/DCD07SET1954.pdf\# page=11>. Acesso em: 05 abril 2017.

Ato Complementar 36, de 1967. Disponível em: <http://www.planalto.gov.br/ccivil_03/ACP/acp-36-67.htm\#art7>. Acesso em: 05 abril 2017.

Superior Tribunal de Justiça. Súmula 436. Disponível em: <http://www.stj.jus.br /SCON/sumulas /enunciados.jsp?vPortalArea=471>. Acesso em: 05 abril 2017.

Supremo Tribunal Federal. ADI 2.006-MC. Disponível em: <http://www.stf.jus.br/portal/constituicao /artigo bd .asp ? item $=\% 201420$ >. Acesso em: 05 abril 2017.

. Embargos no Recurso Extraordinário 94.462. Rel. Min. Moreira Alves. J. Acórdão de 06 de outubro de 1982. Disponível em: $<$ http://redir.stf.jus.br/paginadorpub/paginador.jsp?docTP=AC\&docID=39289>. Acesso em: 05 abril 2017.

CANTO, Gilberto de Ulhôa. Temas de direito tributário. v. III. Rio de Janeiro: Alba, 1964.

CARVALHO, Paulo de Barros. Teoria da norma tributária. São Paulo: Revista dos Tribunais, 1981. 


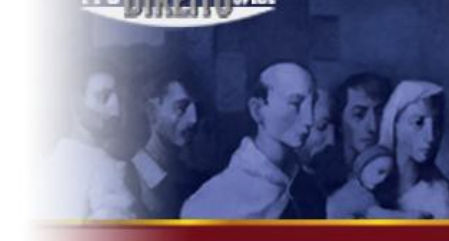

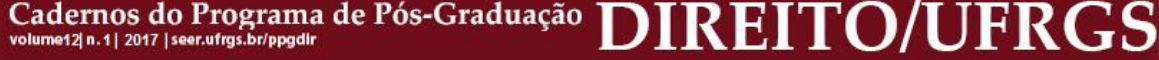

. Curso de Direito Tributário. São Paulo: Saraiva, 2002.

Direito tributário. Fundamentos jurídicos da incidência. São Paulo: Saraiva, 2009.

COELHO, Sacha Calmon Navarro. Curso de direito tributário brasileiro. Rio de Janeiro: Forense, 2009.

FALCÃO, Amilcar de Araújo. Fato gerador da obrigação tributária. São Paulo: Noeses, 2013.

FERRAZ JR., Tercio Sampaio. Introdução ao estudo do direito. Técnica, Decisão, Dominação. São Paulo: Atlas, 2001.

FUNDAÇÃO GETÚLIO VARGAS. Curso online de argumentação jurídica. 2014. Disponível em:http://nc-moodle.fgv.br/ cursos/centro_rec/pag/verbetes/ verbetes5/ juridicizacao htm . Acesso em 22/06/2015.

HENSEL, Albert. Diritto tributario. Milão: Sott. A. Guffrè, 1956.

JARACH, Dino. O fato imponível. Teoria geral do direito tributário substantivo. São Paulo: Revista dos Tribunais, 2004.

MELlO, Marcos Bernardes. Teoria do fato jurídico (plano da existência). São Paulo: Saraiva, 1995.

MIRANDA, Pontes de. Tratado de direito privado. Parte Geral. Tomo I. Rio de Janeiro: Borsoi, 1970.

NABAIS, José Casalta. Direito fiscal. Coimbra: Almedina, 2010.

REALE, Miguel. Lições preliminares de direito. São Paulo: Saraiva, 1994.

SOUSA, Rubens Gomes de. Compêndio de legislação tributária. Rio de Janeiro: Financeiras, 1964.

SILVA, De Plácido e. Vocabulário jurídico. Rio de Janeiro: Forense, 2008.

TUHR, Andreas von. Teoria general del derecho civil aleman. Volumen II. Los hechos jurídicos. Buenos Aires: Depalma, 1947.

XAVIER, Alberto. Do lançamento. Teoria geral do ato, do procedimento e do processo tributário. Rio de Janeiro: Forense, 1998. 


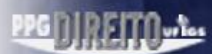

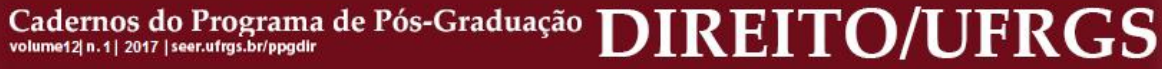

